\title{
A Practical Framework for Cartographic Design
}

\author{
Mark Denil $^{\mathrm{a}}$ \\ ${ }^{a}$ sui generis: Washington,District of Colombia,_USA; mark_denil_maps@hotmail.com
}

\begin{abstract}
Creation of a map artifact that can be recognized, accepted, read, and absorbed is the cartographer's chief responsibility. This involves bringing coherence and order out of chaos and randomness through the construction of map artifacts that mediate processes of social communication. Maps are artifacts, first and foremost: they are artifacts with particular formal attributes. It is the formal aspects of the map artifact that allows it to invoke and sustain a reading as a map. This paper examines Cartographic Design as the sole means at the cartographer's disposal for constructing the meaning bearing artifacts we know as maps, by placing it in a center of a practical analytic framework. The framework draws together the Theoretic and Craft aspects of map making, and examines how Style and Taste operate through the rubric of a schema of Mapicity to produce high quality maps. The role of the Cartographic Canon, and the role of Critique, are also explored, and a few design resources are identified.
\end{abstract}

Keywords: canon, cartography, craft, critique, design resources, design, mapicity, schema, style, taste, theory

\section{Cartographic Design}

Creation of a map artifact that can be recognized, accepted, read, and absorbed is the cartographer's chief responsibility. This involves bringing coherence and order out of chaos and randomness through the construction of map artifacts that mediate processes of social communication.

Maps are artifacts, first and foremost: they are artifacts with particular formal attributes. It is the formal aspects of the map artifact that allows it to invoke and sustain a reading as a map, and, although these formal attributes are of paramount importance, they are seldom directly examined.

I would like, therefore, to take this opportunity to examine these attributes, and to explore how they allow certain artifacts to become maps. Concerns with, and the details of, whatever particular data is underlying any particular map are set aside in this investigation. By doing so, I shall attempt to formally and practically isolate how the artifact mediates that complex process of social communication already mentioned.

There is absolutely nothing whatsoever that is natural about a map: like music, it is a wholly artificial construct that is wholly dependent upon culturally determined conventions. A map exists solely within, is judged exclusively upon, and only operates through, a complex ontological and epistemological structure that allows maps to exist, allows them to be good or bad, and allows them to be employed.

The only tool set the map maker has at his or her disposal in creating the map artifact is that of Cartographic Design. Randy Nakamura $(2004,55)$ noted that although "...design is about analysis and problem-solving, [...] its fundamental impact on the world (for better or for worse) is in the artifacts and form it produces." All maps are designed, but only some are designed well.
Cartographic Design itself is the product of a formal symbiotic relationship between Craft and Theory. On the one hand sits the body of Craft knowledge that has been built by cartographers over centuries of practice and, on the other hand, lies Theory. Theory is the equally significant body of knowledge about what a map is, what it does, and how it works that is shared across a map literate society.

\section{Design and Mapicity}

I have elsewhere proposed (Denil 2012) that there exists, in all map literate communities, a schema of map-ness or map-hood that allows a reader to differentiate between the map and the not-map. The schema is made up of three principle components:

- a paradigmatic vocabulary of appropriate form,

- a grammatical syntax of application, and

- a canon of exemplary idiomatic practice.

Conformity to this schema constitutes Mapicity, which is the quality a map reader recognizes as satisfying the condition of being a map. In short, a map is a map because a map literate reader recognizes a set of attributes in the artifact: attributes that signal to the reader that the artifact in question is a map, and that then go on to guide the reader's employment of the artifact as a map.

Nothing can be a map without satisfying the condition of Mapicity, because Mapicity constitutes the theoretical underpinning of the map: in particular, the vocabulary, syntax, and idiom of the what a map is. By contrast, the map is embodied by means of certain Craft practices: practices that bring the artifact itself into physical existence, and which are primarily concerned with practical elements such as a mastery of means and a culture of materials. In other words, a map is constructed by Craft, and it is within a framework of Mapicity that tacit Craft knowledge is applied. 
The symbiotic relationship between theory and craft is a balance, not unlike the Chinese "two-part Taiji diagram" or "yin-yang symbol" [Fig. 1]. Each individual map represents a balance between theory and craft because both are always present in every map: no map can exist as disembodied theory and even an artifact of pure craftsmanship requires a belief (that is; a theory) that craftsmanship alone is enough.

Striking that balance is the role of Cartographic Design, through the factors of Style and Taste.

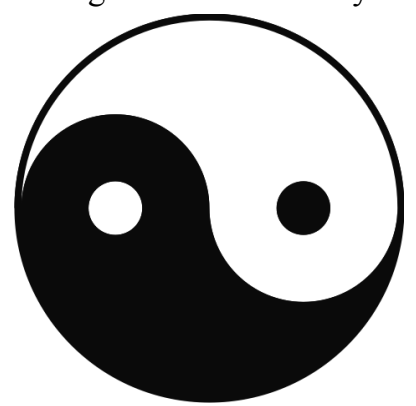

Fig. 1. two-part Taiji diagram or yin-yang symbol

\section{Style and Taste}

The schema of Mapicity provides us a vocabulary of elements, which are accompanied by a syntax of usage that tells us what elements could be appropriately employed in particular circumstances. Clearly there may be several different choices and combinations of elements that may be appropriate in differing circumstances, so the syntax conceptually groups usage practices into coherent Styles.

The term Style is used by in a variety of ways, but I am using it here to refer to distinct varieties of order. These can be observed, for example, at the broadest level, in map taxonomies: topographic, thematic, sketch, and so forth. While these stylistic differences make significant differences in the way maps look and operate in particular detail, they are not fundamental ontological differences: any collection of maps may exhibit different Styles, but they are nonetheless all maps.

The schema of Mapicity, however, does not stop with vocabulary and syntax: it also provides us with a set of approved examples of how to employ stylistic elements: it provides a Canon of good practice. The importance of this Canon must not be underestimated: the Canon forms the horizon against which all maps are situated and judged. Maps in the Canon show us how to make good maps; they exemplify idiomatic usage, and thus constitute Taste.

The operation of the Canon is perhaps the most complex and interesting of the components of Mapicity, but there isn't time to explore it in depth here. Instead, I would like to focus on the role of Design.

\section{Register of Craft Knowledge}

The volume and variety of types of Craft knowledge that operates in cartographic practice is astonishing. Conceptually dividing that variety into registers is useful and convenient; and I propose to call these registers the graphic, the cartographic, and the geographic.
In the geographic register I would place knowledge and understanding of the milieu or situation being mapped. This obviously may well be non-geographic in nature: maps are certainly not exclusively geographic. That term, however, can serve here as a figure of metonymy for all things being mapped, and in any event I am setting that register aside for now.

In the cartographic register I would place knowledge of the sort sometimes referred to as cartographic fundamentals: principles of projection, generalization, symbolization, scale, etcetera. This register forms the core of most cartographic training, and we need not discuss it further here.

What I would like to focus upon, however, is the register I am calling graphic: in particular, space, unity, page architecture, type, and color. This is the body of knowledge about how a graphic is composed and produced. I would also include, as well, reproduction, including pre-press, press work, and post-press, plus paper and other media matters. Graphic Design, even in the best mapping schools, is a woefully thin spot in the curriculum.

It is, nonetheless, critically important. Ezra Pound (1960, 34) told us that poetry is "determined time", and that no one can write poetry who has not studied music. Pound also observed that "design is determined space", and it follows that no one can make a good map without having studied graphic design.

\section{Design Resources}

Fortunately, there are many useful resources available for assisting the map maker in this study.

One of the best is a small book by Alex W. White (2002), called The Elements of Graphic Design: Space, Unity, Page Architecture, and Type. White has also written several other excellent books, but it his Elements of Graphic Design that draws together the disparate parts and concerns, and addresses how graphic elements fit together and interact on a page (or screen, as the case may be).

In addition, Kimberly Elam's (2004) book Grid Systems: Principles of Organizing Type offers a solid, comprehensive, step by step approach to composing pages of increasing complexity. Elam ignores content to focus on text as abstract texture within a composition; centralizing the organization of graphic entities in the graphic field. She also critiques possible solutions, demonstrating ways to think about page architecture. Too many would-be map makers cannot organize a page.

There are a tremendous range of resources about type available, many of them very good. A book like The Elements of Typographic Style by Robert Bringhurst (2004) offers an encyclopedic look at type and type usage that, as one reviewer wrote: “...successfully combines the personal with the practical, the philosophical with the truly useful."

Because Bringhurst's Elements may, by itself, be a bit rarefied and esoteric, we can turn to Ellen Lupton's Thinking With Type: A Critical Guide for Designers, 
Writers, Editors, \& Students (Lupton 2004). Lupton usefully discusses practical issues and presents good examples of innovative work. She even demonstrates how it may be permissible to break the rules; judgment about which is one of the hardest skills to acquire.

I will end this list with a work that was revolutionary when it appeared in 1928, and sadly indeed, still qualifies as groundbreaking and necessary in 2017, at least in cartographic circles. Although Jan Tschichold himself later disavowed some of its more doctrinaire pronouncements, The New Typography (Tschichold 1995) remains solidly useful reading and guidance. Because cartography has only superficially absorbed many of the lessons of modernism, this founding document of modernist design is still exceptionally relevant.

As all these resources tell us, Graphic Design is more than just a set of rules: remember, it is in the artifacts created that it has its fundamental impact. To understand how design resources can be judiciously applied, we need to step back a bit and consider how we bring judgment into the design process.

\section{The Role of Critique}

You may recall that I earlier identified Style as distinct variety of order that provides a set of appropriate choices afforded by the schema of Mapicity. I define Taste as the ability to, first, distinguish Stylistic features and then to use this ability to make value judgments based on cultural criteria. From this it follows that while Styles are categories of appropriate choices, and Taste is what allows us to navigate amongst the choices, the acquisition, cultivation, and refinement of Taste, beyond the most rudimentary level, is achieved through Critique.

Critique is a method for disciplined, systematic analysis of a discourse. Ultimately, it is a reasoned account of the map artifact; of its embodiment, its meaning, its function, and its value. As an account, it must be plausible (meaning reasonable, because supported with evidence), coherent (that is, clear and reasonably organized), and rhetorically effective (that is to say, expressed appropriately and persuasively).

Critique is made up of description, interpretation, analysis, and evaluation, and must be clearly situated in a theoretic construct that can itself be examined, questioned, and challenged. That theoretic construct is Mapicity, and represents a set of deliberate or unconscious choices. It is, in the end, all a matter of choice: we can only read on a map that which we read into it. Maps do not reproduce the world, but they are constructed in such a way as to persuade us to choose to see them as reproducing the world. We choose what we will see as truth using the tools and postulates given us by our interpretive communities as Mapicity, and we apply the tools and postulates on the features delivered to us on the map by Cartographic Design.

\section{Conclusion}

Existence of the map, as a map, relies on a schema of Mapicity. The outward signs of mapicity are manifested through Cartographic Design, a process which determines the form of the artifact. Design itself incorporates both Theoretical and Craft aspects that co-exist in a symbiotic relationship. The balance between Theory and Craft, and between competing factors within each of them, can be thought of as Taste; and Taste is the judgmental manifestation of the schema of Mapicity. The Mapicity schema is inculcated in map readers and in map makers by the implicit and explicit education they receive from their communities. This education is delivered through many channels, but the most sophisticated and complex level of that education is informed and engaged Critique.

All maps are designed. Like most aspects of cartographic practice, maps can be well designed or otherwise, and a design practice can be informed or naive. While I submit that one is more likely to get consistently good maps from an informed practice than from one based on luck or faith, we will no doubt continue to see both informed and naïve practices. Still, the centrality of design to all cartographic practice is irrefutable, and the difference design makes is all the difference in the world.

\section{References}

Bringhurst, Robert. (2004). The elements of typographic style. Point Roberts, WA: Hartley \& Marks.

Denil, Mark. (2012). A Disquisition on Cartographic Style and Taste: with Attendant Remarks upon Aesthetics, Clarity, Design, and Mapicity. Cartographic Perspectives $73: 75-88$ http://www.cartographicperspectives.org/index.php/jour nal/article/view/cp73-denil/826. Accessed 4 February 2017.

Elam, Kimberly. (2004). Grid systems: Principles of Organizing Type. New York: Princeton Architectural Press.

Lupton, Ellen. (2004). Thinking with type: a critical guide for designers, writers, editors, and students. New York: Princeton Architectural Press.

Nakamura, Randy. (2004). The Grand Unified Theory of Nothing. Emigre, 67, p55.

Pound, Ezra. (1960). The ABC of Reading. New York: New Directions. p34

Tschichold, Jan. (1995). The New Typography: A Handbook for Modern Designers. Berkeley: University of California Press.

White, Alex. (2002). The Elements of Graphic Design. New York: Allworth Press. p1 